\title{
The Effectiveness of Debt Relief: Assessing the Influence of the HIPC Initiative and MDRI on Tanzania's Health Sector
}

\author{
Fernando Lopez Oggier \\ Center for American Politics and Public Policy, University of California at Los Angeles, Los Angeles, CA \\ bttps:/ / doi.org/10.33697/ ajur.2019.021 \\ Student:fernando.lopezoggier@ucla.edu*,flopezoggier@gmail.com \\ Mentor:desveaux@ucla.edu
}

\begin{abstract}
Debt relief initiatives have been part of the international development sphere since the early 1990s. With the launch of the Heavily Indebted Poor Country (HIPC) Initiative in 1996 and the Multilateral Debt Relief Initiative (MDRI) in 2005 many countries have been able to successfully qualify for debt relief. Tanzania has been one of the primary beneficiaries of debt relief over the years. While empirical evidence demonstrates that the country's economic growth has been positively impacted by debt relief initiatives, other aspects of human development need to be analyzed to ensure a comprehensive assessment of the HIPC Initiative and the MDRI. This study compiles Tanzania's health data into a composite indicator to perform a graphical analysis to compare the trends between health outcomes and external debt. The graphical analysis is contextualized through a qualitative analysis of political, economic and health financing literature from the Bank of Tanzania, UNICEF and USAID. The results indicate that health outcomes improved throughout the whole study's time period particularly after the HIPC Initiative. The health financing literature also points to increased development expenditure during this period. Nonetheless, the effects of debt relief seem to diminish in the long-term due to fluctuations in external donors and logistical barriers to budget execution. Tanzania also continues to face socio-economic and geographic disparities in health outcomes and funding. Some of the literature also states that the country's weak system of checks and balances and the lack of robust institutions could cause opportunistic policy preferences that might not necessarily improve Tanzania's health sector.
\end{abstract}

\section{KEYWORDS}

Child Mortality Rate; Debt Relief; External Debt; Heavily Indebted Poor Country Initiative; International Monetary Fund; Life Expectancy; Maternal Mortality Rate; Multilateral Debt Relief Initiative; Official Development Aid; Prevalence of

Undernourishment

\section{INTRODUCTION}

Debt relief for heavily indebted countries has been a pressing subject since the 1990s. The World Bank and the International Monetary Fund (IMF) have established two primary debt relief programs over the years: the Heavily Indebted Poor Country (HIPC) Initiative in 1996 and the Multilateral Debt Relief Initiative (MDRI) in 2005. The HIPC Initiative was designed to ensure that the world's poorest countries weren't saddled with unmanageable debt. In order to qualify for debt relief countries implemented a set of socio-economic reforms to diminish poverty and encourage economic growth. ${ }^{1}$ The MDRI, established in 2005 , is an extension of the HIPC Initiative providing 100\% cancellation of multilateral debts owed by HIPC countries to the World Bank, IMF and African Development Bank. ${ }^{2}$

The goal of these initiatives, and debt relief as a whole, is to increase a government's fiscal space. Fiscal space is defined by Peter Heller as "room in a government's budget that allows it to provide resources for a desired purpose without jeopardizing the sustainability of its financial position or the stability of the economy." 3 The fiscal space created by debt relief programs should allow recipient countries to make meaningful progress in various sectors of society, namely infrastructure, health and education. This should in turn increase the country's human development attainment.

As of 2013, 35 countries have reached the "completion point" of these debt relief initiatives. Tanzania has been one of the primary beneficiaries of debt relief over time, qualifying for assistance in 2000 under the HIPC Initiative and 2005 under the MDRI. Various studies have demonstrated that these initiatives have positively impacted Tanzania's economic growth. ${ }^{4}$

However, economic growth and GDP figures are not exact proxies for human development and don't form a comprehensive analysis of a country's socioeconomic progress. While these countries were able to decrease their debt service payments and increase their fiscal space, it's important to assess how well this translated into tangible improvements in society. This assessment 
can be done through the lens of Tanzania's progression through debt relief. Instead of attempting to evaluate every area that qualifies as "human development", the impacts on the country's health sector can be specifically analyzed in order to narrow the purview of the research. The World Health Organization (WHO) has outlined in several of its reports the fundamental role that better health plays in human development as well as the link between health and poverty reduction. ${ }^{5}$ Hence, the question to be addressed is what influence did the HIPC Initiative and the MDRI have on Tanzania's health sector?

Official development aid (ODA) and debt relief are some of the most important sources of development assistance. For most low income countries, ODA and debt relief are their largest foreign financial inflows, especially given their restricted access to international markets. Thus, when large-scale development programs like the HIPC Initiative and the MDRI are established, assessing their effects on different sectors of human development is crucial. These initiatives tend to encourage and foster economic growth, theoretically allowing governments to allocate more funding towards other sectors of society instead of debt service payments. Nonetheless, it's important to evaluate whether this is resulting in meaningful improvements. GDP and economic figures alone cannot map these outcomes. If increased fiscal space through debt relief is not allowing for financial resources to trickle down to fundamental sectors of society, such as the health sector, debt relief isn't really a meaningful form of development assistance. However, if there are substantial improvements in Tanzania's health sector post-debt relief as opposed to the years prior to receiving assistance, then there is a strong argument to be made about the success of debt relief programs.

\section{Background}

Debt relief was brought to the international stage in the 1990s through movements like the Jubilee 2000 campaign, an international coalition of NGOs and other organizations that called for the cancellation of debt in developing economies by the year 2000. The campaign was quite successful in pushing debt relief onto the agenda of Western governments and international organizations. ${ }^{6}$ Ultimately, the World Bank and the IMF established their own debt relief programs starting with the HIPC Initiative in 1996. However, after receiving criticism that highlighted the lengthy and restrictive requirements to qualify for debt relief, the World Bank and the IMF "enhanced" the HIPC Initiative by loosening the qualifying thresholds in 1999.4 Tanzania qualified for debt relief under the enhanced HIPC Initiative in 2000 after demonstrating commitment to poverty reduction and macroeconomic stability. ${ }^{1}$

\section{Literature Review}

The majority of the literature surrounding the analysis of debt relief, namely the HIPC Initiative and the MDRI, focuses on the economic and fiscal ramifications of such initiatives. Most studies analyze the relationship between debt relief initiatives and economic growth or the fiscal responses that ensue.

Gomera (2014) cites that there is a positive correlation between debt relief and economic growth, stating that this correlation is especially significant amongst primary benefactors of debt relief like Tanzania. The empirical evidence demonstrates that on average debt service payments from the recipient countries have declined by 2\% of their GDP. From 1990 - 2010 Tanzania received US\$7,573,760,000 in the form of debt relief; during this period Tanzania's annual GDP also grew by an average of almost 6\%.4 Moreover, Gomera further states that debt relief recipients have demonstrated improved debt sustainability and economic growth compared to other low income countries that were not recipients of debt relief assistance. ${ }^{4}$

Other research also determines that debt relief programs allow countries to improve their public financial behavior in a desired way ${ }^{7}$ by offering opportunities to improve their investments and domestic resources. ${ }^{8}$

Another study finds that debt relief initiatives increase average income per household and decrease the percentage of people below the poverty line. ${ }^{9}$ Moreover, the study also states that "the proportion of income needed to transfer the poor above the poverty line... significantly reduced over the [time] period [analyzed]."9

Nonetheless, some literature finds different results. Dijemu (2018) investigated the trends in public investment at the decision and post-completion points of the enhanced HIPC Initiative and MDRI. On one hand the study found that there are increases in public investment of around 2 and 3 percent at the decision and post-completion points of the enhanced HIPC Initiative respectively. ${ }^{10}$ However, when it comes to the MDRI, Dijemu doesn't find any impacts on growth or public investment. In addition, this research also didn't find heterogeneous impacts on growth as a result of the enhanced HIPC Initiative and argues that improvements in institutional quality need to be made for debt relief to have meaningful effects on growth and investment. ${ }^{10}$ Thus, there is literature that points towards debt relief not having a substantial effect on increasing growth like some of the other studies do.

Additionally, some previous research has also been conducted surrounding the effects of multilateral debt on child health across multiple countries. Welander (2016) assessed the impacts of the HIPC Initiative on infant mortality across 56 countries and found 
that after debt relief a country's infant mortality rate decreases by an average of $0.5 \% .11$ This correlates with around 3,000 less infant deaths per heavily indebted poor country. Welander states that the empirical evidence indicates that health outcomes for infants born to poor mothers improve even more after debt relief assistance. The study found a $0.9 \%$ drop in deaths amongst infants born to poor mothers. Nonetheless, Welander's results found that there are no statistically significant child health effects from graduating the program and receiving full debt relief.11

This study seeks to build on the foundation laid out by the current debt relief literature by taking the assessment of the HIPC Initiative and the MDRI one step further. Thus, this study evaluates whether the improvements in economic growth and fiscal response provided by these debt relief initiatives are resulting in tangible improvements in the health sector as a whole. As stated previously, if positive outcomes in human development aren't present in recipient countries despite increases in fiscal space, these initiatives aren't meaningful and should be amended.

\section{Hypothesis}

Theoretically, debt relief initiatives should provide governments with increased fiscal space for investment into social expenditure. Evidently, debt relief isn't the only way for governments to create fiscal space. For instance, governments can raise revenues through tax reforms, re-prioritize expenditure and improve government efficiency which would allow for increased government spending. Nonetheless, debt relief is still a very direct way of creating fiscal space for impoverished countries that are saddled with unmanageable debt. Furthermore, since developing economies are in greater need of increased social expenditure and often lack the ability to respond to fiscal challenges, having more fiscal space is a pressing issue. ${ }^{12}$

Given that increased social expenditure should allow for tangible improvements in Tanzania's health sector, I hypothesize that the HIPC Initiative and the MDRI have facilitated the ability for Tanzania to make considerable advances in health performance. Nevertheless, there are other variables that can affect the country's ability to perform. Inefficient allocation of funds and lack of general guidance need to be taken into account as they can always impact the final outcomes of debt relief programs.

\section{METHODOLOGY AND PROCEDURES Case Study}

As stated previously, Tanzania has been one of the main recipients of debt relief over the years. Tanzania qualified for $\$ 3$ billion in debt service relief under the enhanced HIPC Initiative after implementing its own set of economic reforms. ${ }^{13}$ By 2005 , Tanzania had further qualified to receive 100\% debt relief under the MDRI which amounted to $\$ 297$ million. ${ }^{14}$ As outlined in the literature review, studies demonstrate that this assistance positively impacted Tanzania's economy. Debt relief was sacrosanct in helping the country fulfil Goal 8D of the Millennium Development Goals relating to debt sustainability and management. ${ }^{3}$ Since Tanzania is one of the more successful beneficiaries of debt relief, the country is an exemplary case study to identify whether debt relief programs result in meaningful improvements in human development. Additionally, there is substantial availability of healthrelated data for Tanzania in order to map out the country's health performance over time. ${ }^{15}$

\section{Data Calculations}

The purview of the research spans from 1995 - 2015 in order to analyze Tanzania's health sector performance before and after being impacted by debt relief assistance. In order to assess the effects of the HIPC Initiative and the MDRI on Tanzania's health sector, data from the World Bank and different United Nations agencies is compiled to create a model that acts as a proxy for health performance. This Health Index is a geometric mean of various health statistics to create a composite indicator similar to how the Human Development Index (HDI) is set up. The HDI compiles life expectancy, mean years of schooling, expected years of schooling and GNI per capita to produce a value from $0-1$. This value is representative of that country's performance in human development. A value closer to 0 represents poorer human development while a value of 1 represent excellent human development attainment. In order to convert the indicators into indices with a score from $0-1$ minimum and maximum values (goalposts) are established. ${ }^{16}$ The maximum values are the highest observed values for that time series. The United Nations Development Programme (2015) states that the rationale behind minimum values is based on the values that society needs to survive over time. Once these values are defined, sub-indices are calculated for each indicator using the following formula:

$$
\text { Dimension index }=\frac{\text { actual value-minimum value }}{\text { maximum value-minimum value }}{ }^{17}
$$


This study will compile the following statistics to calculate the Health Index: life expectancy (LE) ${ }^{\mathbf{A}}$, child mortality ratio per 1,000 births $(\mathrm{CMR})^{\mathbf{B}}$, maternal mortality ratio per 100,000 births $(\mathrm{MMR}){ }^{\mathrm{C}}$, and prevalence of undernourishment amongst the population $(\mathrm{PoU})^{\mathbf{D}}$. However, the formula for the dimension index presented above that the UN uses to calculate the HDI only works for statistics where a higher value represents a better outcome, such as with life expectancy. When it comes to child mortality, maternal mortality and undernourishment, higher figures represent poorer health sector performance. Hence, the formula must be truncated so that the score of $0-1$ assigned to each statistic is consistent in mapping out health performance. Therefore, the truncated dimension index formula is as follows:

$$
\text { Truncated Dimension index }=1-\left(\frac{\text { actual value }- \text { minimum value }}{\text { maximum value }- \text { minimum value }}\right)
$$

The geometric mean is then found by multiplying all the sub-indices together and finding the $x$ root of the product where $x$ is the number of sub-indices used: ${ }^{17}$

$$
\sqrt[x]{\text { Product of } x \text { subindicies }}
$$

Hence, the geometric mean for the Health Index is calculated using the following formula:

$$
\sqrt[4]{L E \text { subindex } \times \text { CMR subindex } \times \text { MMR subindex } \times \text { PoU subindex }}
$$

\section{Justification for Maximum and Minimum Values}

The UNDP states that the minimum value for life expectancy is 20 years because historical evidence indicates that if life expectancy in a society drops below the typical age of reproduction the society would die out. ${ }^{15}$ Moreover, from 2014 onwards the maximum value for life expectancy has been 85 according to the UNDP and that's what has been used for this model. ${ }^{15}$

When it comes to a country's maternal mortality ratio per 100,000 births (MMR), the UNDP states that countries where the ratio exceeds 1,000 deaths do not differ in their inability to create supportive conditions for maternal health. Countries with a ratio of 10 or fewer deaths per 100,000 births are performing at a level where any differences in their ratios are random. ${ }^{17}$ Hence, the MMR's maximum and minimum values for the dimension index calculations will be 1,000 and 10 respectively.

FAO's prevalence of undernourishment indicator $(\mathrm{PoU})$ measures "the share of the population that has a caloric intake which is insufficient to meet the minimum energy requirements necessary for a given individual". 18 The scale does not include countries below 5\% so it can be argued that there's not much difference in a country's ability to feed its population if values drop below $5 \%$. Moreover, the scale goes up to $60 \%$ so it is also justifiable that if a country's PoU goes over $60 \%$ there's not much difference in its persistence of food insecurity. Thus, 60 and 5 will be the PoU's maximum and minimum values respectively.

Based on the minimum and maximum value rationales by different UN agencies for these statistics, similar justifications can be made for child mortality per 1,000 births (CMR). The CMR has been under 200 deaths in all countries since 1980 according to the UN WPP. ${ }^{19}$ Hence, it can be inferred that comparing CMRs above 200 wouldn't indicate much of a difference in a country's health performance. Moreover, in the same way that a MMR below 10 doesn't indicate any substantial dissimilarity in health performance, a CMR below 5 deaths per 1,000 births doesn't make much of a difference in health attainment either. Therefore, the maximum and minimum values for CMR are 200 and 5 respectively.

\section{Graphical Analysis}

Using Tanzania's Health Index scores for each year within the stated time frame, the country's health performance can be mapped out. In order to compare the country's performance with the HIPC Initiative and the MDRI, Tanzania's External Debt

A The Human Development Index uses life expectancy as one of its subindicies

B UN WPP (2017) provides annual data for child mortality rate for all countries from 1950 onwards

C The World Bank (2015) provides data for maternal mortality starting in 1990

D FAO, IFAD, UNICEF, WFP and WHO (2018) provide undernourishment prevalence data for countries between 5\% and 60\% undernourishment 
in billions ${ }^{\mathbf{E}}$ is mapped out alongside health performance. The health index scores are multiplied by 10 for the graphical analysis so that the highest score is 10 rather than 1 . This makes the scale for the health index scores more similar to the scale for external debt (in \$bn) which allows for a clearer comparison. The years where HIPC and MDRI were granted are also marked out.

\section{Qualitative Analysis}

Finally, in order to take into account Tanzania's socioeconomic and political context, a qualitative analysis using literature from the Tanzanian government, UNICEF, USAID as well as key political scientists and economists is presented. This analysis offers internal and external public finance information surrounding debt management as well as the policies Tanzania has in place to allocate funds. Moreover, the qualitative analysis examines both temporal and fixed factors that affect Tanzania's health expenditure and health outcomes. Finally, overarching explanations for the potential inefficiency of resource allocation are also discussed in the qualitative analysis. Literature from organizations like UNICEF provides a third party perspective on health financing and a more objective analysis that can further contextualize the graphical analysis.

\section{Results and Discussion}

Appendix A includes all the statistical data compiled to make the Health Index. Appendices B - E include the results of the calculations for each subindex using the dimension index formula as well as the truncated dimension index formula from the Methodology.

The tables below include Tanzania's Health Index score and External Debt in billions (USD) ${ }^{20,21}$ for the study's time frame. The scores range from $0-1$. A value closer to 0 represents poor health performance whereas a score closer to 1 represents exemplary health performance.

\begin{tabular}{|c|c|}
\hline Year & $\begin{array}{c}\text { Health Index } \\
\text { Score }\end{array}$ \\
\hline 1995 & 0.202 \\
\hline 1996 & 0.223 \\
\hline 1997 & 0.246 \\
\hline 1998 & 0.272 \\
\hline 1999 & 0.301 \\
\hline 2000 & 0.327 \\
\hline 2001 & 0.352 \\
\hline 2002 & 0.378 \\
\hline 2003 & 0.401 \\
\hline 2004 & 0.424 \\
\hline 2005 & 0.449 \\
\hline 2006 & 0.476 \\
\hline 2007 & 0.505 \\
\hline 2008 & 0.529 \\
\hline 2009 & 0.539 \\
\hline 2010 & 0.553 \\
\hline 2011 & 0.568 \\
\hline 2012 & 0.586 \\
\hline 2013 & 0.602 \\
\hline 2014 & 0.617 \\
\hline 2015 & 0.627 \\
\hline
\end{tabular}

\begin{tabular}{|c|c|}
\hline Year & $\begin{array}{c}\text { External Debt in } \\
\text { billions (USD) }\end{array}$ \\
\hline 1995 & 8.0 \\
\hline 1996 & 7.5 \\
\hline 1997 & 7.6 \\
\hline 1998 & 7.4 \\
\hline 1999 & 7.7 \\
\hline 2000 & 7.7 \\
\hline 2001 & 6.8 \\
\hline 2002 & 6.8 \\
\hline 2003 & 6.8 \\
\hline 2004 & 6.6 \\
\hline 2005 & 7.3 \\
\hline 2006 & 8.2 \\
\hline 2007 & 4.6 \\
\hline 2008 & 4.4 \\
\hline 2009 & 5.4 \\
\hline 2010 & 6.9 \\
\hline 2011 & 7.6 \\
\hline 2012 & 9.5 \\
\hline 2013 & 11.6 \\
\hline 2014 & 13.8 \\
\hline 2015 & 15.9 \\
\hline
\end{tabular}

Table 1. Health Index Score over time.

Table 2. External Debt in billions (USD) ${ }^{20,21}$ over time.

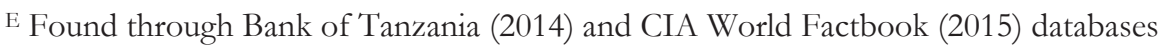




\section{Graphical Analysis}

In order to analyze debt service and health performance fluctuations over time, both variables have been mapped in a linear graph. As mentioned previously, the health index scores have been multiplied by 10 in order to facilitate the graphical comparison in Figure 1.

\section{Tanzania's External Debt (\$bn) and Health Index Score (out of 10) over time}

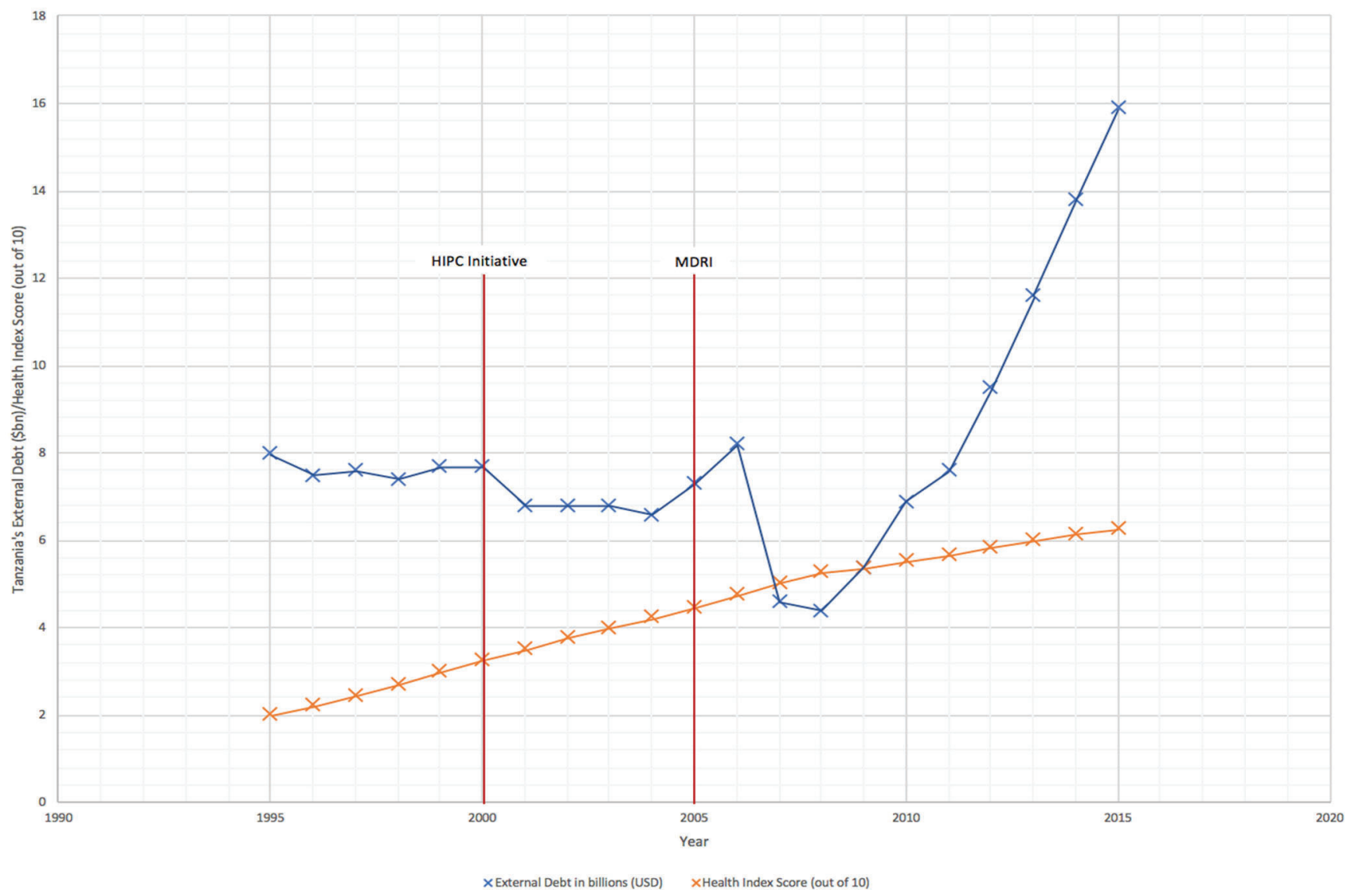

Figure 1: Tanzania's External Debt (\$bn) and Health Index Score (out of 10) throughout the study's time frame

As depicted in Figure 1, health performance has steadily increased whereas total debt service has wavered but has still considerably decreased since 1995. It is important to note that Tanzania's total debt service was already significantly decreasing before receiving debt relief assistance in 2000. However, from the period following the HIPC Initiative (2000 - 2005) Tanzania's Health Index score increased by 1.22 (0.122) whereas during the pre-debt relief period (1995 - 1999) it increased by $0.99(0.099)$, meaning that the increase in health after the HIPC Initiative is slightly higher. Additionally, the period after the MDRI (2005 2010) also saw a slightly higher score increase than the pre-debt relief period of 1.04 (0.104). Nevertheless, the long-term postdebt relief period $(2011$ - 2015) only saw an increase of 0.59 (0.059) in the country's Health Index score. However, Tanzania's external debt has increased quite steadily since 2009, 4 years after the MDRI. This substantial increase in external seems to overlap with the slower improvements in health outcomes. Despite this, Tanzania's Health Index score is still slowly increasing over time.

\section{Qualitative Analysis}

The literature on Tanzania's health expenditure can contextualize the graphical analysis by identifying temporal factors that affect how the government is allocating its resources and whether debt relief assistance was significant in impacting health outcomes. 


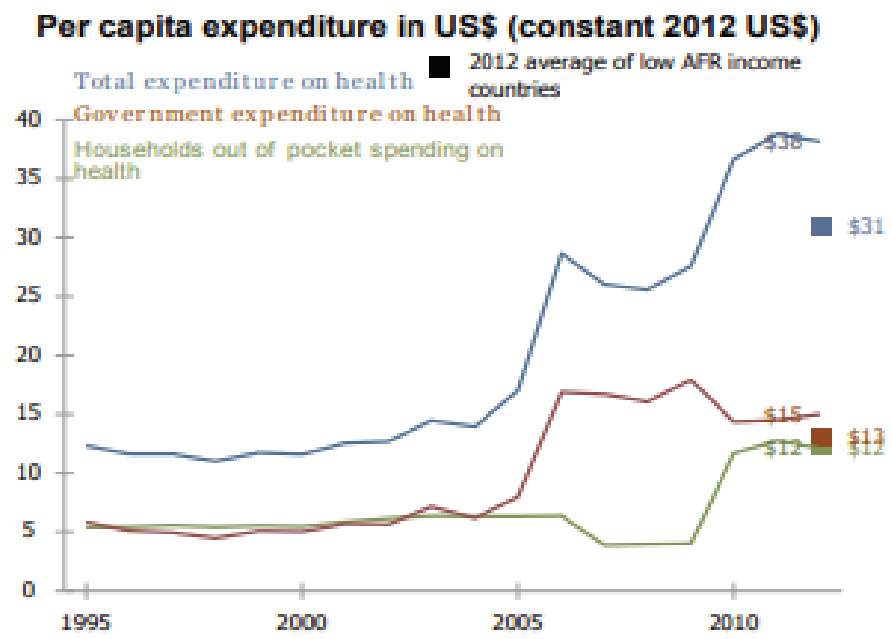

Figure 2: World Health Organization (2014) depicting Tanzania's per capita health expenditure from $1995-2012$

These temporal factors include: per capita health expenditure trends, levels of foreign donors over time, net ODA received and comparing recurrent versus development spending. Moreover, the research also indicates fixed factors, namely geographic and socioeconomic disparities, that provide health financing challenges which increased fiscal space might not be addressing. Finally, the literature also provides overarching explanations for why African states might allocate resources towards public sectors less effectively.

As part of USAID's Health Policy Project, a five year cooperative to strengthen developing countries' health programming and governance, USAID published Health Financing Reports providing an overview of how different countries invested in their health sectors. ${ }^{22}$ Tanzania's Health Financing Report states that from 2002 - 2013 per capita expenditure has been slowly increasing, reaching US $\$ 49$ in 2013 which compares quite favorably to the other countries in the region. ${ }^{22}$ As seen in Figure $2,{ }^{23}$ there has been some stagnation in total health expenditure in recent years, but the increase has been steady since the late-2000s. The graph depicts a spike in government expenditure on health right after 2005 which is the year that Tanzania qualified for MDRI assistance. However, since this spike the government's expenditure has stagnated and fluctuated, decreasing from 2009 onwards. This is also when Tanzania's total debt service began to stagnate, eventually increasing in 2013.

Another temporal element of Tanzania's health financing is foreign donors. A significant portion of Tanzania's health expenditure comes from foreign donors which are not depicted in Figure 2. UNICEF reports that over one third of total health care spending is accounted for by foreign resources which is far above the sub-Saharan average. ${ }^{24}$ Since 1995 Tanzania's foreign resource contribution has consistently been higher than the sub-Saharan mean. While there have been fluctuations over the years, the margin has increased on average, bringing foreign contributions to $35.9 \%$ by 2014 . However, from $2010-2014$ these external resources have decreased by almost $4 \% .{ }^{24}$ Referring back to Table 1 , this drop in external resources correlates with a slower increase in Health Index scores. During the years when external resource contributions were increasing, there was a slightly steeper increase in Health Index scores. ${ }^{24}$

It is important to note that other forms of aid can influence health outcomes. Certain fluctuations in health index patterns might be explained by tracking ODA (Official Development Aid) in Tanzania over the study's time period. As depicted in Figure 3, Tanzania's net ODA increased relatively steadily from 1995 to 2007 by about $\$ 2$ bn. ${ }^{25}$ According to health index scores, health outcomes also increased steadily during this period. However, since 2007 ODA has fluctuated more with a recent drop in 2013. ${ }^{25}$ During these recent fluctuations the growth in health index scores also slowed. In addition, from 2013 to 2015 the score growth was even slower. Thus, it could be argued that ODA contributions played a role in health outcomes, possibly even more so than debt relief. Nonetheless, it's also important to note that some forms of debt relief are accounted for in ODA. 


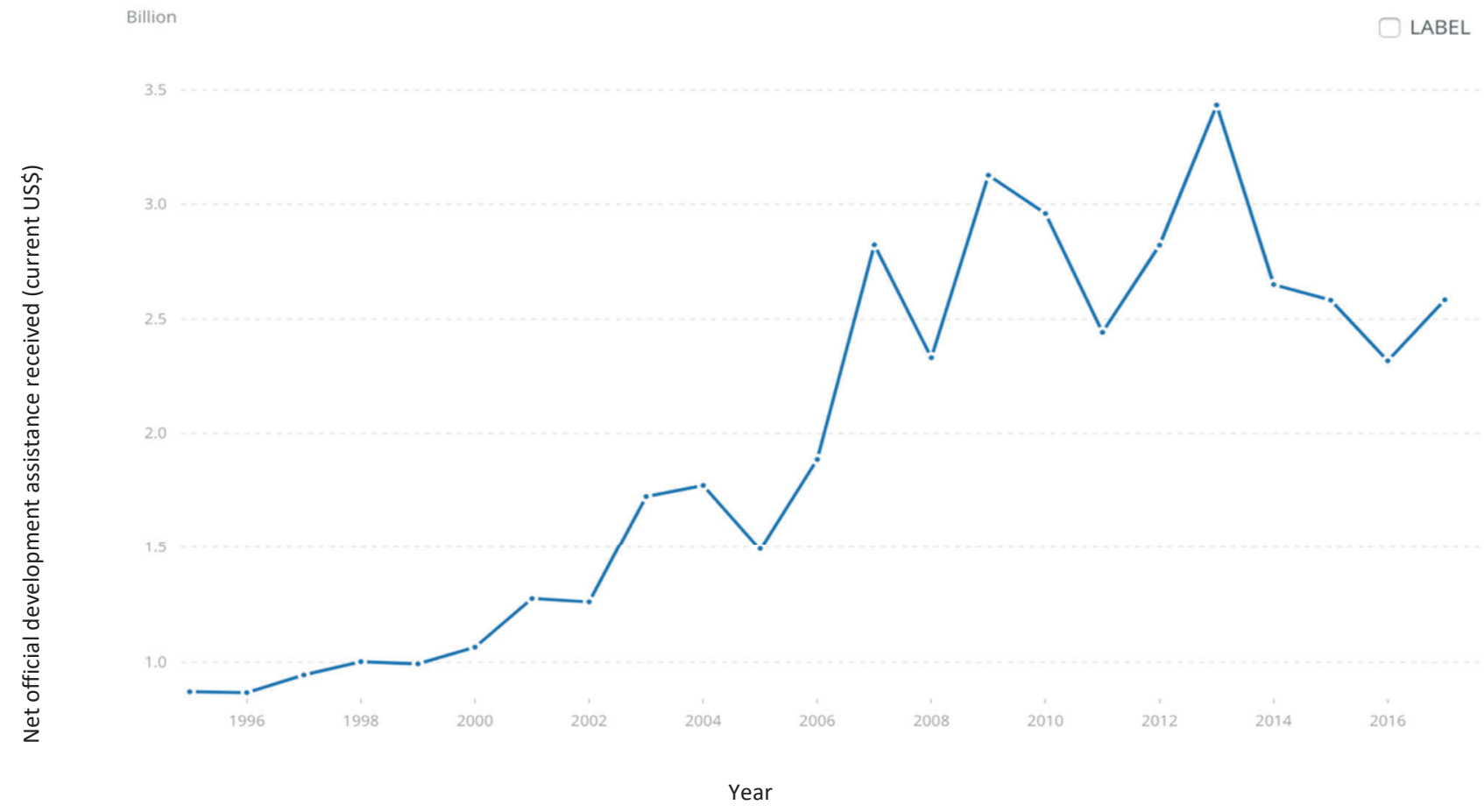

Figure 3: World Bank Net ODA received in Tanzania over time ${ }^{25}$

Moreover, another key distinction that needs to be made to assess health expenditure trends over time is the difference between recurrent and development spending. Tanzania allocates the majority of its health care budget to recurrent spending (salaries, personal emoluments, commodities and other charges) rather than development spending (capital, health technology and other additions). According to Tanzania's Ministry of Finance, since 1995 recurrent expenditure has made up the majority of the government's total expenditure. Nonetheless, development expenditure increased relatively steadily from $1999-2010$ by $18.5 \%$ whereas the preceding years saw $\left(1995\right.$ - 1999) saw inconsistent fluctuations. ${ }^{26}$ This could also explain the slightly faster improvement in health outcomes following the HIPC Initiative: the Tanzanian government was allocating more of its health care budget to development expenditure while debt service payments were decreasing. Nevertheless, the portions of recurrent and development spending have been fluctuating recently. Development spending significantly decreased from 2013 to 2015 . The average recurrent budget was $72.3 \%$ in recent years whereas the development budget was $27.7 \%{ }^{26}$ Hence, Tanzania's health expenditure has been partly exaggerated by recurrent spending leading to less funding for capital improvements and other additions. ${ }^{27}$ This also means that the fluctuations in recent years could have had an influence over the $2011-2015$ trends in health outcomes.

In addition to these temporal elements, the government of Tanzania also faces challenges that are more fixed over time. Firstly, there are many logistical barriers to budget execution. The health budget's development spending execution is only $81 \%$ compared to the $91 \%$ execution of the recurrent budget in the 2013/14 fiscal year. The development budget execution was even lower in the 2012/13 fiscal year at 69\%.27 In previous years the recurrent execution of the health budget has consistently been higher than the development execution. ${ }^{28}$ The Tanzanian government's Health Sector Public Expenditure Review states that budget performance continues to be hindered by "the low absorption capacity of the spending units; delays in the release of funds; non-release of the funds; over-ambitious budgeting... and lengthy and cumbersome procurement processes". ${ }^{28}$ Another logistical error that the government has made is the allocation of funds to different districts. In Tanzania, health sector resources are distributed from the central government to the local governments based on an allocation formula that takes into account district demographics. The implementation of this formula lacks thoroughness given that there is considerable variance between the allocation predicted by the formula and the actual allocation. This has led to funding disparities between districts. ${ }^{24}$ These logistical barriers make the implementation of development projects less efficient and can affect health outcome data.

Another fixed barrier to improving health outcomes in Tanzania is the country's socio-economic and geographic disparities which pose a challenge to efficiently tackling health. UNICEF's budget brief states that "child mortality, nutrition status, vaccination 
coverage and likelihood of attending a health facility to deliver a baby are still heavily determined by; location, wealth and the education of a mother". ${ }^{29}$ This creates geographic disparities in health care accessibility. Central Tanzania has a vaccination coverage for children of $83 \%$ whereas the Southwest Highland only reaches $67 \%$. Moreover, in rural areas $44.2 \%$ of births are at home compared to $12.8 \%$ in urban areas. ${ }^{29}$ Thus, it is evident that even if development expenditure was increasing due to increased fiscal space from 2000 - 2010, Tanzania still continues to see substantial inequities in the availability and accessibility of health resources.

In addition to the temporal and fixed elements that might affect the quantitative patterns, there is also substantial literature that can provide more comprehensive explanations for the reasons why Tanzania and other African states struggle to effectively invest in social services.

Some research indicates that many African countries do not provide social services to their citizenry due to preferences or resource constraints. Robert Bates discusses how the characteristics of African governments, namely their economies and political institutions, can influence their policy decisions. Humphreys and Bates discuss that states that have immobile economic bases have a higher likelihood of engaging in predation..$^{30}$ Moreover, weak institutions and political instability can also affect policy choice. Many African governments that suffer from political instability exhibit opportunistic behavior. ${ }^{30}$ For instance, Robert Bates discusses how various African states use agricultural policies to recompense political supporters. In many cases, rather than letting market forces determine price points, the government acts as a monopsony and buys all the crops from farmers at a fixed price that's lower than the market price. The government provides subsidies and loans in order to keep production at these artificially low prices. Although all producers stand to benefit, this still allows the government to pick which farmers win and which don't. ${ }^{31}$ In addition, governments that are less constrained also exert more freedom over policy choices than governments that have robust checks and balances. Tanzania's political system has a weak structure of checks and balances which allows for a system that's dominated by the Presidency, the Executive and the Chama Cha Mapinduzi (CCM) party (the dominant ruling party in Tanzania). Although the country's institutional framework does include some checks and balances, the Legislature and other official entities have a limited formal capability to restrain the Executive. ${ }^{32}$ This facilitates the government's ability to engage in opportunistic behavior and follow its own set of policy preferences.

Another overarching theory for the weakness of Tanzania's institutions is Jeffrey Herbst's work on the power of African states. Herbst theorizes that the lack of solid institutions in Africa and the prevalence of state failure is due to the continent's statebuilding experience. Africa did not have the same international pressures for war-making that medieval Europe experienced. European state-building occurred under systematic pressures, such as scarcity of land and the presence of densely populated regions, which promoted state consolidation. ${ }^{33}$ On the other hand, Africa was a sparsely populated continent and precolonial African states did not have to face many of the survival imperatives that Europe did. They did not have the need to amass state power over rural terrain. The geographic features of Africa encouraged shared distribution of power and states did not have to exert strict control over their territories. African farmers invested in small slices of land due to the continent's low population density. If harsh rulers emerged farmers could easily flee rather than fight. This meant that trying to impose complete control over a particular region was very difficult so shared sovereignty became the standard. Thus, unlike Europe, Africa never developed a Westphalian notion of sovereignty and state borders. ${ }^{33}$ Additionally, during colonialism the European powers that divided Africa had little incentives to develop the region's institutions. Their focus was on resource exploitation. After independence, the enforcement of arbitrary colonial borders on Africa made it even more difficult for them to adopt a survival mandate. Herbst argues that this caused African states to develop without having the strong and responsive economic, physical and political infrastructure that European states were able to develop. ${ }^{33}$

\section{CONCLUSIONS}

An important consideration for any type of economic-related development program is whether tangible advancements are being made in society beyond improvements in economic figures. In assessing how debt relief has impacted health outcomes in Tanzania, this study used graphical and qualitative analyses for the years prior to debt relief assistance as well as the years following it.

The findings from the graphical analysis suggested that debt relief had a beneficial impact on health outcomes in the short-term compared to the pre-debt relief period. The qualitative analysis partly corroborates these findings given that development expenditure did increase during the short-term period $(2000-2010)$. However, the improvements in health outcomes during the short-term could have also been influenced by foreign donors that aren't affected by debt relief. Since foreign donor contributions increased in the mid-2000s this might have played a role in improving health outcomes during this time. ${ }^{24}$ Moreover, the health financing literature suggests that there were factors not accounted for in debt relief assistance that influenced health outcomes in the long-term. These include the 4\% drop in foreign donor contributions from $2010-2014$ as well as the logistical barriers to budget allocation and execution. It should also be noted that there were significant fluctuations in development expenditure in 
recent years. ${ }^{26}$ Moreover, there are also some explanations for why African states might be less efficient at allocating resources to the public sector. Firstly, political instability and weak institutions can influence policy choice. When there aren't robust checks and balances, as is the case in Tanzania, the government can more easily engage in opportunistic behavior and follow its own policy preferences. ${ }^{30}$ Additionally, the lack of state-building experience that African states had in the pre-colonial era as well as the challenges that colonialism imposed on such states impaired their ability to develop robust institutions. ${ }^{33}$ In general, the lack of efficiency in Tanzania's public spending is most likely an amalgamation of the previously stated explanations as well as the temporal and fixed elements described.

These findings aren't completely consistent with the hypothesis, which predicted that debt relief would increase fiscal space and allow for more health care spending in turn improving health outcomes. Although debt relief does increase fiscal space, it's not always the case that this fiscal space will be invested in improving health outcomes. The graphical analysis does indicate that debt relief had a positive impact on health outcomes in the period after the HIPC initiative. The qualitative analysis also points to substantial increases in development expenditure during this period. However, the results indicate that in the long term the effects of debt relief are diminished. As stated previously, from 2011 - 2015 development expenditure fluctuated and there were smaller increases in Tanzania's Health Index Score. The hypothesis also predicted that logistical barriers could affect the efficiency of increased spending which was supported by the health financing literature.

While debt relief programs increase fiscal space and might allow for some tangible socio-economic improvements, they can still be amended to increase their efficacy. Tanzania is regarded as the poster child of debt relief; however, the country still faces lots of challenges and doesn't always see satisfactory outcomes. Tanzania experiences considerable logistical barriers to its health budget execution and is prone to fluctuations in expenditure. If Tanzania were to receive logistical support and guidance along with debt relief assistance the country could make the most of its increased fiscal space. It's important to note that in order to qualify for the enhanced HIPC Initiative countries needed to demonstrate a commitment to poverty reduction and a stable macroeconomic environment. ${ }^{1}$ However, these commitments should be maintained post-debt relief as well. Additionally, logistical assistance in budget execution and allocation of funds would also allow Tanzania to reduce some of the geographic disparities and underperformance it currently sees. Although debt relief is an important form of assistance for developing economies, it does not generate new resources. Thus, it is important to maximize and correctly allocate the resources that debt relief can free up. If nation-wide development projects provided more logistical assistance and guidance, developing countries might see more consequential outcomes, and national inequities in resource availability and accessibility could be significantly curtailed.

\section{ACKNOWLEDGEMENTS}

The author thanks Professor James Desveaux, Andrea Vilán, PhD and anonymous reviewers for crucial suggestions, edits and revisions to the content of the manuscript as well as their support throughout the research process. The author also thanks the Center for American Politics and Public Policy at UCLA and their Quarter in Washington program for making this research possible.

\section{REFERENCES}

1. International Monetary Fund, (2000) Press Release: IMF and IDA Support Debt Relief for Tanzania. 5 April. bttps:// www.imf.org/en/News/Articles/2015/09/14/01/49/pr0026 (Accessed September 30, 2018)

2. International Monetary Fund. (2017) Debt Relief Under the Heavily Indebted Poor Countries (HIPC) Initiative. Factsheet, IMF \& World Bank, 1-4.

3. Heller, Peter (2005) Understanding Fiscal Space. IMF Policy Discussion Paper. Fiscal Affairs Department, International Monetary Fund.

4. Gomera, Jumanne Said. (2014) Impact of Debt Relief on Economic Growth in Heavily Indebted Poor Countries.Masters Thesis. Seoul National University.

5. World Health Organization. (2006) Health and development. 30 March. https://www.who.int/hdp/en/ (Accessed September 25, 2018)

6. Johnson, Harold J. (1998) Developing Countries: Status of the Heavily Indebted Poor Countries Hipc Debt Relief Initiative. Washington, D.C.: United States General Accounting Office.

7. Cassimon, Danny, and Bjorn Van Campenhout. (2008) Comparative Fiscal Responce Effects of Debt Relief: an Application to African HIPCS. South Africal Journal of Economics 76 (3): 427-442.

8. Cassimon, Danny, Marin Ferry, Marc Raffinot, and Bjorn Van Campenhout. (2013) Dynamic Fiscal Impact of The Debt Relief Initiatives on African Highly Indebted Poor Countries (HIPCs). Working paper, DIAL (Développement, Institutions et Mondialisation), Paris, France, 24 
9. Osei-Fosu, Anthony Kofi. (2010) Three Essays on Economic Impact Assessment of the Use of the HIPC intiative for Poverty Reduction in Ghana. Thesis, Department of Economics, Kwame Nkrumah University of Science and Technology, Kumasi, Kumasi, Ghana.

10. Dijmeu, Eric W. (2017) The impact of the Heavily Indebted Poor Countries initiative on growth and investment in Africa. Journal Article, World Development 104: 108-127.

11. Welander, Anna. (2016) Does Debt Relief Improve Child Health? Evidence from Cross-Country Micro Data. Working Paper, Department of Economics, School of Economics and Management Lund University, Lund, Sweden.

12. Heller, Peter. (2005) Back to Basics -- Fiscal Space: What It Is and How to Get It. Finance and Development 42 (2).

13. International Monetary Fund. (2001) Press Release: IMF and World Bank Support US $\$ 3$ billion In Debt Service Relief For Tanzania Under Enhanced HIPC Initiative. 27 November. bttps://wmw.imf.org/en/News/Articles/2015/09/14/01/49/pr0148 (Accessed September 30, 2018)

14. International Monetary Fund. (2005) Press Release: IMF to Extend 100 Percent Debt Relief to Tanzania Under the Multilateral Debt Relief Initiative. 23 December. https:// wmw.imf.org/en/News/Articles/2015/09/14/01/49/pr05304 (Accessed September 2018, 2018)

15. United Nations Development Programme. (2010) What is the rationale behind the minimum values for indicators? 5 November. http:// hdr.undp.org/en/content/what-rationale-bebind-minimum-values-indicators (Accessed October 3, 2018)

16. United Nations Development Programme. (2015) Human Development Report. Washington, D.C.

17. United Nations Development Programme. (2015) Human Development Report - Technical notes. Washington, D.C.

18. FAO, IFAD, UNICEF, WFP and WHO. (2018) The State of Food Security and Nutrition in the World 2018. Rome, Italy.

19. United Nations Population Division. (2017) World Population Prospects: The 2017 Revision. (Department of Econonics and Social Affairs).

20. Bank of Tanzania (2014) Publications and Statistics. June 15. bttps:// wmw.bot.go.tr/Publications/publications AndStatistics.asp (Accessed June 21, 2019)

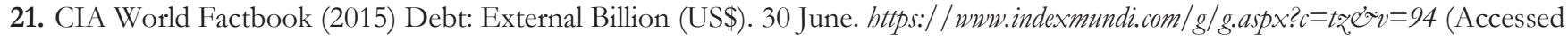
June 21, 2019)

22. USAID. (2016) Health Financing Profile Tanzania. Factsheet, Health Policy Project, Washington, DC, 2.

23. World Health Organization. (2014) WHO Global Health Expenditure Atlas. Geneva, Switzerland: WHO Press.

24. UNICEF. (2016) Health Budget Brief Tanzania FY 2011/12-FY 2015/16. Summary Report, 1-12.

25. World Bank. (2017) Net official development assistance received (current US\$). April 22. https:/ / data.worldbank.org/indicator/DT.ODA.ODAT.CD (Accessed July 4th 2019)

26. Ministry of Finance and Economic Affairs. (2010) Budget Digests 2004/5 - 2010/11. Digest, Dodoma, Tanzania: Government of Tanzania.

27. USAID. (2015) Prospects for Sustainable Health Financing in Tanzania. Baseline Report, Health Policy Project, Washington, D.C.: U.S. Government, 1-27.

28. Ministry of Health and Social Welfare. (2012) Health Sector Public Expenditure Review. Dar-es-Salaam, Tanzania: Government of Tanzania.

29. UNICEF. (2018) Health Budget Brief 2018 Tanzania. Summary Report, 1-12.

30. Humphreys, Macartan, and Bates, Robert. (2005) Political Institutions and Economic Policies: Lessons from Africa. British Journal of Political Science 35 (3): 403-428.

31. Bates, Robert, and Lofchie, Michael. (1980) Agricultural Development in Africa: Issues of Public Policy. New York: University of California, Los Angeles.

32. Lawson, Andrew and Rakner, Lise (2005). Understanding Patterns of Accountability in Tanzania. Synthesis Report, Oxford Policy Management, Chr. Michelsen Institute, Research on Poverty Alleviation.

33. Herbst, Jeffrey. (2000) African States and Power. Princeton University Press.

34. World Bank. (2015) Maternal mortality ratio (modeled estimate, per 100,000 live births). bttps:// data.worldbank.org/indicator/SH.STA.MMRT?locations=TZ. (Accessed September 25, 2018)

\section{ABOUT THE STUDENT AUTHOR}

Fernando Lopez Oggier is an undergraduate student at the University of California, Los Angeles (UCLA) that will graduate in June 2020. He is pursuing a Bachelor of Arts in Political Science and a Bachelor of Arts in Geography. Fernando aims to pursue a career in international affairs and hopes to attend graduate school.

\section{PRESS SUMMARY}

In 1996 The World Bank and the International Monetary Fund established for the first time a debt relief program for countries that had been saddled with unmanageable debt. High levels of debt can inhibit sustainable development and prosperity. These debt relief programs aimed to reduce debt service payments and allow countries to allocate their budgets to other sectors of 
society. Previous research demonstrates that a country's economic growth is positively impacted by debt relief initiatives.

However, this study aimed to analyze whether freeing up a government's budget through debt relief allows for prosperity in other sectors of society. The case study that this research focused on is Tanzania given that the country has been a primary recipient of multiple debt relief initiatives. Instead of attempting to evaluate every area that qualifies as "human development", the impacts on the country's health sector can be specifically analyzed in order to narrow the purview of the research. Increased health attainment is a critical aspect of human development and plays a fundamental role in poverty reduction. Therefore, this study compiled Tanzania's health data into a composite indicator to compare health outcome trends with the country's external debt. Health financing information from the Bank of Tanzania, UNICEF and USAID as well as political science literature contextualized this analysis. The study found that health outcomes improved in the short term period after the HIPC Initiative; the health financing literature also pointed to increased development expenditure during this time period. However, the effects of debt relief seemed to diminish in the long-term due to fluctuations in external donors and logistical barriers to budget execution. Some overarching explanations also stated that the country's weak system of checks and balances and the lack of robust institutions could cause opportunistic policy preferences that might not necessarily improve Tanzania's health outcomes. The country also continues to face socio-economic and geographic disparities in health outcomes and funding.

\section{APPENDICES}

Appendix A: The statistics compiled to calculate Tanzania's Health Index: life expectancy ${ }^{16}$, maternal mortality ${ }^{34}$, child mortality ${ }^{19}$, and undernourishment ${ }^{18}$

\begin{tabular}{|c|c|c|c|c|}
\hline Year & Life Expectancy & $\begin{array}{c}\text { Maternal Mortality Ratio (per } \\
100,000 \text { births) }\end{array}$ & $\begin{array}{l}\text { Child mortality (per } \\
1,000 \text { births) }\end{array}$ & $\begin{array}{l}\text { Percentage of population } \\
\text { that is undernourished }\end{array}$ \\
\hline 1995 & 49.5 & 961 & 163.9 & 32.1 \\
\hline 1996 & 49.6 & 944 & 159.5 & 34.5 \\
\hline 1997 & 49.9 & 924 & 154.1 & 35.6 \\
\hline 1998 & 50.3 & 900 & 147.6 & 36.3 \\
\hline 1999 & 50.8 & 870 & 140.1 & 36.3 \\
\hline 2000 & 51.5 & 842 & 131.8 & 36.8 \\
\hline 2001 & 52.3 & 813 & 123.1 & 37.1 \\
\hline 2002 & 53.2 & 777 & 114.7 & 37.8 \\
\hline 2003 & 54.1 & 747 & 106.8 & 37.7 \\
\hline 2004 & 55.2 & 717 & 99.8 & 37.7 \\
\hline 2005 & 56.2 & 687 & 93.7 & 36.7 \\
\hline 2006 & 57.2 & 652 & 88.5 & 35.4 \\
\hline 2007 & 58.2 & 608 & 83.7 & 34.2 \\
\hline 2008 & 59.2 & 566 & 79.2 & 33.8 \\
\hline 2009 & 60 & 542 & 75.7 & 34.5 \\
\hline 2010 & 60.9 & 514 & 71.9 & 34.7 \\
\hline 2011 & 61.7 & 483 & 68.5 & 34.7 \\
\hline 2012 & 62.5 & 464 & 65.8 & 33.4 \\
\hline 2013 & 63.3 & 438 & 63.4 & 32.7 \\
\hline 2014 & 64.2 & 418 & 60.9 & 32.1 \\
\hline 2015 & 65 & 398 & 58.8 & 32.1 \\
\hline
\end{tabular}

\begin{tabular}{|c|c|}
\hline \multicolumn{1}{|c|}{ Appendix $\boldsymbol{B}$} \\
\hline Year & Life Expectancy Sub index \\
\hline 1995 & 0.454 \\
\hline 1996 & 0.455 \\
\hline 1997 & 0.460 \\
\hline 1998 & 0.466 \\
\hline 1999 & 0.474 \\
\hline 2000 & 0.485 \\
\hline 2001 & 0.497 \\
\hline 2002 & 0.511 \\
\hline 2003 & 0.525 \\
\hline 2004 & 0.542 \\
\hline 2005 & 0.557 \\
\hline 2006 & 0.572 \\
\hline 2007 & 0.588 \\
\hline 2008 & 0.603 \\
\hline
\end{tabular}




\begin{tabular}{|l|l|}
\hline 2009 & 0.615 \\
\hline 2010 & 0.629 \\
\hline 2011 & 0.642 \\
\hline 2012 & 0.654 \\
\hline 2013 & 0.666 \\
\hline 2014 & 0.680 \\
\hline 2015 & 0.692 \\
\hline
\end{tabular}

\begin{tabular}{|c|c|}
\hline \multicolumn{2}{|c|}{ Appendix $C$} \\
\hline Year & Child Mortality Sub index \\
\hline 1995 & 0.185 \\
\hline 1996 & 0.208 \\
\hline 1997 & 0.235 \\
\hline 1998 & 0.269 \\
\hline 1999 & 0.307 \\
\hline 2000 & 0.350 \\
\hline 2001 & 0.394 \\
\hline 2002 & 0.437 \\
\hline 2003 & 0.478 \\
\hline 2004 & 0.514 \\
\hline 2005 & 0.545 \\
\hline 2006 & 0.572 \\
\hline 2007 & 0.596 \\
\hline 2008 & 0.619 \\
\hline 2009 & 0.637 \\
\hline 2010 & 0.657 \\
\hline 2011 & 0.674 \\
\hline 2012 & 0.688 \\
\hline 2013 & 0.701 \\
\hline 2014 & 0.713 \\
\hline 2015 & 0.724 \\
\hline
\end{tabular}

Appendix D

\begin{tabular}{|c|c|}
\hline Year & Maternal Mortality Sub index \\
\hline 1995 & 0.039 \\
\hline 1996 & 0.057 \\
\hline 1997 & 0.077 \\
\hline 1998 & 0.101 \\
\hline 1999 & 0.131 \\
\hline 2000 & 0.160 \\
\hline 2001 & 0.189 \\
\hline 2002 & 0.225 \\
\hline 2003 & 0.256 \\
\hline 2004 & 0.286 \\
\hline 2005 & 0.316 \\
\hline 2006 & 0.352 \\
\hline 2007 & 0.396 \\
\hline 2008 & 0.438 \\
\hline 2009 & 0.463 \\
\hline 2010 & 0.491 \\
\hline 2011 & 0.522 \\
\hline 2012 & 0.541 \\
\hline 2013 & 0.568 \\
\hline 2014 & 0.588 \\
\hline 2015 & 0.608 \\
\hline
\end{tabular}

Appendix $E$

\begin{tabular}{|c|c|}
\hline Year & Undernourishment Sub index \\
\hline 1995 & 0.507 \\
\hline 1996 & 0.464 \\
\hline 1997 & 0.444 \\
\hline 1998 & 0.431 \\
\hline 1999 & 0.431 \\
\hline 2000 & 0.422 \\
\hline 2001 & 0.416 \\
\hline 2002 & 0.404 \\
\hline 2003 & 0.405 \\
\hline
\end{tabular}




\begin{tabular}{|c|c|}
\hline 2004 & 0.405 \\
\hline 2005 & 0.424 \\
\hline 2006 & 0.447 \\
\hline 2007 & 0.469 \\
\hline 2008 & 0.476 \\
\hline 2009 & 0.464 \\
\hline 2010 & 0.460 \\
\hline 2011 & 0.460 \\
\hline 2012 & 0.484 \\
\hline 2013 & 0.496 \\
\hline 2014 & 0.507 \\
\hline 2015 & 0.507 \\
\hline
\end{tabular}

